https://helda.helsinki.fi

\title{
Subjective financial situation and financial capability of young adults in Finland
}

\section{Ranta, Mette}

2018-11

Ranta , M \& Salmela-Aro , K 2018 , ' Subjective financial situation and financial capability of young adults in Finland ' , International Journal of Behavioral Development , vol. 42 , no. 6 , pp. 525-534 . https://doi.org/10.1177/0165025417745382

http://hdl.handle.net/10138/311388

https://doi.org/10.1177/0165025417745382

acceptedVersion

Downloaded from Helda, University of Helsinki institutional repository.

This is an electronic reprint of the original article.

This reprint may differ from the original in pagination and typographic detail.

Please cite the original version. 
Running head: FINANCIAL CAPABILITY OF YOUNG ADULTS

Subjective financial situation and financial capability

of young adults in Finland

\begin{abstract}
A key developmental task in young adulthood is acquiring financial capability (Serido, Shim, \& Tang, 2013), meaning competent financial management skills and the responsibilities that these involve. This study extends previous research on the theoretical model of the development of financial capability, including financial confidence (or financial self-efficacy) and financial behavior as factors contributing to subjective and financial well-being. It is part of the Finnish Educational Transitions Studies (FinEdu) longitudinal research project. Participants were 418 young adults aged 24-25 at Time 1 and 26-27 at Time 2. Path and mediation models and Structural Equation Modeling following a modified theoretical model of financial capability were estimated. The results support the theoretical model of financial capability among young adults in Finland. The study complements previous research by investigating the associations between subjective financial situation and financial capability and their respective mediation effects over time.
\end{abstract}

Keywords: financial situation, subjective well-being, young adult, financial capability, longitudinal study 
Global economic upheavals since the late 2000s have created unfavorable prospects and prolonged financial dependency for many young adults (Lee \& Mortimer, 2009). Furthermore, financial difficulties may challenge life management and impair selfconfidence (Cunnien, MartinRogers, \& Mortimer, 2009). Yet, gaining financial independence and economic security form a core psychological developmental task in young adulthood (Arnett, 2000; Hellevik \& Settersten, 2012). One of the key developmental milestones of the transition to adulthood is the acquisition of financial independence, which brings increased responsibility for and control over one's personal life and requires competent life management skills (Shim, Xiao, Barber, \& Lyons, 2009; Shim, Barber, Card, Xiao, \& Serido, 2010). Life management in the financial domain can be understood from the novel theoretical perspective of youth financial capability as a developmental model for understanding the process of acquiring the financial knowledge and behaviors needed to manage adult social roles and responsibilities (Serido, Shim, \& Tang, 2013).

With the increasing need for effective financial decision-making occasioned by the multiple financial problems facing many consumers today, measuring individuals' financial literacy or financial knowledge has become important, yet received little attention in previous studies (Huston, 2010). Financial literacy or financial knowledge have also typically been studied using various indicators and to model outcomes in financial behavior instead of being studied objectively (Huston, 2010). Many studies have also reported that a poor financial situation is related to a low level of life satisfaction or subjective well-being (Cummins, 2000; Diener \& Biswas-Diener, 2002; Jorgensen, Jamieson, \& Martin, 2010). However, very little attention has been paid to how young adults gain the confidence 
required for financial life management or to their subjective perceptions based on subjective experiences, despite the high psychological value of gaining financial independence (Lee \& Mortimer, 2009). In fact, recent definitions of financial literacy highlight that individuals do not only need the necessary objective knowledge for financial decision-making and behavior but also the "ability and confidence" to apply that knowledge (Asaad, 2015; Serido et al., 2013). Furthermore, the differences in the developmental contexts of youth have not been properly acknowledged in terms of the development of financial life management in young adulthood. Research is also lacking on how economic conditions affect well-being through financial management. In sum, life course theorists have suggested that research on individual development should take the differences in the multiple levels of context into account, from the sociohistorical macrolevel context with its institutionalized trajectories and societal structures and conditions, to the individual micro-level including subjective experiences of developmental processes (Elder, 1998; Mayer, 2003).

In response, this two-wave longitudinal study focuses on the financial situation of young adults in the midst of societal financial uncertainty due to the global economic downturn. More specifically, we investigated the applicability of the theoretical model of financial capability as a developmental process among the young adult population in Finland. We specify three dimensions of financial capability for young adults seeking to manage their social roles and responsibilities: financial confidence (or financial selfefficacy), financial behavior and subjective and financial well-being (Joo \& Grable, 2004; Serido et al., 2013). Although financial knowledge, both objective and subjective, is the starting point in the development of financial capability according to its theoretical model 
(Serido et al., 2013), multiple studies have found that subjective financial knowledge is more strongly associated with young adults' behavioral outcomes in comparison with objective financial knowledge (see e.g., Seay \& Robb, 2013; Xiao, Serido \& Shim, 2011). These findings support the use of a subjective measure, financial confidence, defined also as self-assessed or perceived financial knowledge (Asaad, 2015). Therefore, the present study acknowledges the importance of financial confidence and in line with the financial capability theoretical model, uses financial confidence (or financial self-efficacy) which is one of the three factors of financial self-beliefs. It has also been defined as belief, selfreliance and confidence in one's economic behavior (Lee \& Mortimer, 2009). Self-beliefs are formed through understanding financial concepts that are related to the financial ability to cope with everyday financial demands. In addition to financial confidence (or financial self-efficacy), self-beliefs also include financial attitudes informed by responsible financial practices and perceived behavioral control or belief that one's behavior will lead to an expected outcome based on past experiences and expected barriers (Serido et al., 2013; Shim et al., 2009).

Financial capability theorizing states that differences in financial confidence (or financial self-efficacy) may influence financial behavior, which in turn affects subjective and financial well-being. Furthermore, in order to account for the individual-level differences in developmental contexts, we supplemented this model with longitudinal information on young adults' subjective financial situation to consider how subjective financial situation impacts the process of financial capability development over time while gaining self-sufficiency in the transition to adulthood. 


\section{Gaining financial independence in the Finnish context}

Finland offers an intriguing context for research on young adults' financial life management and the transition to financial independence. Steady growth in young people's incomes in the past three decades was interrupted by the early 1990s recession which severely hit young adults moving out of their childhood home (Lintonen, Wilska, Koivusilta, \& Konu, 2007; Wilska \& Lintonen, 2016). Currently, Finland is recovering from yet another economic recession that began in 2008, with 2014 youth unemployment rates being 18\% from age 15 to 24, and 9\% from age 25 to 34 (Official Statistics of Finland, 2014). While the Nordic social-democratic welfare state provides young adults with equal opportunities for financial independence irrespective of family socioeconomic background, the effects of these recent recessions have been severe. For example, an economic downturn means reduced labor market opportunities for young people frequently working alongside studying, increased youth unemployment rates and structural changes in working life. Moreover, in relatively wealthy countries such as Finland, the effects could be beyond monetary ones such as income and employment. A recession may also have a negative impact on subjective well-being, inducing increased feelings of insecurity and stress (UNICEF Office of Research, 2014).

Students in Finland receive state financial support in the form of study grants, housing benefits and state-guaranteed study loans. Loans aside, these are benefits that do not need to be repaid. Living costs are high, however. Young adults perceive their financial situation as challenging with $61 \%$ reporting difficulties in making ends meet (Ministry of Education and Culture, 2014). Finnish youth make the transition to financial independence at a fairly young age, moving out of their childhood home at approximately age 20, men 
being slightly older (Choroszewicz \& Wolff, 2010). The Finnish educational pathway includes three years of upper secondary education (vocational and/or general academic track) and at age 19 students apply for entry to higher tertiary-level education at universities and polytechnics and/or seek employment (Finnish National Board of Education, 2012). This higher education application period is characterized by demanding entrance examinations and stiff competition for limited places. If unsuccessful, the transition is prolonged to not only further education with often multiple gap years, but to adulthood in general. This has led to the societal problem of Finnish higher educational graduates not entering the labor market until ages 25 to 29, later than elsewhere in Europe (Ministry of Education and Culture, 2010).

In sum, it is crucial to consider the Finnish societal setting, with early financial independence and self-sufficiency during the economic recession, high costs of living, and expectations of the welfare state to provide financial support. We aim to extend present knowledge on youth financial capability by applying the model in this setting. In this respect, revising the model with the novel addition of young adults' subjective financial situation is also supported.

\section{Literature review on the components of youth financial capability}

Financial capability has been defined as "multiple aspects of knowledge and behavior related to how individuals manage resources and make financial decisions" (FINRA, 2009, p. 5; Serido et al., 2013, p. 287). It can be investigated both from an objective approach and from a subjective approach. In the objective approach, financial capability is defined based on available household financial resources, and in the subjective approach, on personal 
perceptions of managing the household economy (Leskinen \& Raijas, 2006). According to Atkinson and colleagues, financial capability includes knowledge, understanding, skills, and responsibilities in four areas: 1) day-to-day money management, 2) planning ahead, 3) choosing products, and 4) staying informed (2006; see also Leskinen \& Raijas, 2006). In addition to developing and understanding financial knowledge and skills, financial capability includes "gaining access to financial instruments, institutions and services" (Johnson \& Sherraden, 2007). This perspective is based on the theorizing on capability of Sen (1993) and Nussbaum (2002), incorporating notions of freedom and opportunities to lead one's life as desired within the parameters set by the external environment and one's internal capabilities, and so contributing to well-being (Johnson \& Sherraden, 2007).

It is generally known that financial literacy is important for financial behavior and decision-making (Lusardi, Mitchell, \& Curto, 2010). The accumulation of financial literacy or financial capability is a dynamic and complex process, as it evolves and develops over time through education and experiences (Huston, 2010; Serido et al., 2013). Financial literacy is formed through knowledge about financial concepts and products along with the understanding, self-confidence and effective application of personal finance-related information (Huston, 2010). More specifically, financial knowledge can be either objective, including managing information concerning income, wealth, loans, savings and investments and the macro-economy, or as in the present study, subjective, meaning personal evaluation of one's financial management (Shim et al., 2010). Overall, financial capability requires not only this knowledge, but also the ability to apply that knowledge and act accordingly (Asaad, 2015; Dixon, 2006). This ability is based on the use of self-beliefs, a self-regulating mechanism combining previous knowledge and new experiences. In line 
with Bandura's (1977; 1989) Social Cognitive Theory, Serido and colleagues regard these self-beliefs with three factors: financial attitudes, perceived behavioral control and, as in the present study, financial self-efficacy, defined as belief in being capable of performing a particular (financial) behavior.

In sum, financial behavior "emerges through an interaction between individual agency (e.g., abilities) and the environment (e.g., opportunities)" (Serido et al., 2013, p. 288). Financial behavior is also directly linked with well-being (Serido et al., 2013). Research has long acknowledged the link between subjective well-being and material resources, such as income (Luhmann, Schimmack, \& Eid, 2011). Well-being can be studied through, for example, domain-specific factors such as the individual's financial situation, or general well-being (e.g., life satisfaction) (Diener, Emmons, Larsen, \& Griffin, 1985; Shim et al., 2010). Financial well-being or financial satisfaction, defined as satisfaction with life management and the financial resources available, and having a low level of debt, is influenced by personal characteristics, financial behaviors, and life events, such as experiencing financial distress (Joo \& Grable, 2004; Kim, Garman, \& Sorhaindo, 2003). Among the micro-level factors of personal characteristics, the most important are age, gender, household type, place of residence, and the family's socio-economic status, including income and level of education (Gutter \& Copur, 2011; Joo \& Grable, 2004; Wilska \& Lintonen, 2016).

With the current understanding on the strong link between financial situation and well-being and the present societal economic turbulence, it is justifiable to include young adults' subjective perception of their current income level to investigate not only financial well-being, but also whether, and, if so in what ways, subjective financial situation and the 
other components of financial capability are related. Young adults have often been identified as economically vulnerable due to their irregular income levels and changing life situations, including the transition from the childhood home to independent living, and transitions between educational levels and the labor market, and increasingly so in the current instable macroeconomic climate (Conger, Conger, \& Martin, 2010). This vulnerability may also be due to incompetent decision-making and lack of sufficient skills and knowledge (Morgan, Schuler, \& Stoltman, 1995; Smith \& Cooper-Martin, 1997). Life changes may be associated with uncertainty and pessimistic future plans, along with increasing financial responsibilities (Arnett, 2004). At a general level, instability in the transition to adulthood can lead to low life satisfaction (Danzinger \& Ratner, 2010; Heckhausen, 1999; Luyckx, De Witte, \& Goossens, 2011). Perceived financial challenges and an economic recession have also been seen to negatively affect well-being and reduce youth adjustment and sense of control or mastery, in other words, confidence in the ability to influence future outcomes in life (Conger, Conger, Matthews, \& Elder, 1999; Elder \& Caspi, 1988).

In conclusion, as the array of financial needs, resources and responsibilities vary at different life stages, economic theories have also emphasized that the financial capability needed for making informed decisions cannot be seen as a stable characteristic. Income and consumption levels differ, as do present-day economic environments. Inevitably, the significance of money in everyday life also changes with age. In the teenage years, money is a resource for emancipation and identity construction, whereas in the transition to adulthood it is accompanied with economic independence and societal integration (Cunnien et al., 2009; Sherraden, Johnson, Guo, \& Elliott, 2011; Wilska \& Lintonen, 2016). The 
financial habits that form during the transition to adulthood are likely to persist throughout adulthood (Shim et al., 2010), and hence optimal financial behavior adopted in adolescence and young adulthood, such as saving habits, may transfer into adulthood (Ashby, Schoon, \& Webley, 2011; Friedline, Elliott, \& Nam, 2011).

\section{The present study}

Within financial capability attainment, young adults prepare for complex life decisions, "facilitating a positive transition to adulthood during widespread economic uncertainty" (Serido et al., 2013, p. 287). Therefore, the diverse and demanding transitions that take place in young adulthood may have a profound effect on well-being, especially the transitions related to career development, which are often marked by an irregular and uncertain income and the transition to independent living (Cowan, 1991). Studies on young adults' psychological development, however, have not often taken the financial domain into account, albeit that young adults have the opportunity and the desire to acquire financial management skills and habits (Shim et al., 2009). Moreover, only a few studies have investigated the relatively new concept of young adults' financial capability (Serido et al., 2013).

To contribute to filling this gap, the present study investigated the applicability of the hypothesized theoretical financial capability model among Finnish young adults (Figure 1). The aim is to examine how economic conditions and experiences affect subjective wellbeing in the critical young adulthood stage of the life course. However, this study extends the previous research by using the components of financial capability, including subjective 
well-being, financial confidence (or financial self-efficacy), financial behavior and financial well-being, as a predictive model with latent variables rather than a correlated change model used in the followed study. It is, however, assumed that the determinants of financial capability from a developmental perspective are similar (Hypothesis 1, H1) (Serido et al., 2013).

Insert Figure 1. here.

As young adults in Finland are financially independent at an early stage in contrast to their peers in many countries, such as the United States where college students are heavily financially influenced by their parents (Shim et al., 2009; 2010), it is assumed that the financial capability strategies adopted by young adults in Finland are at a high level. It is also assumed that positive development of co-occurring patterns of financial confidence (or financial self-efficacy) and financial behavior increase these young adults' financial and subjective well-being (Hypothesis 2, H2) (Gutter \& Copur, 2011; Otto, 2013).

Financial satisfaction has received little attention in empirical research, at least as a conceptual framework inclusive of its multidimensional factors (Joo \& Grable, 2004). In this study, in addition to individual factors, subjective perceptions of the personal financial situation are included to depict the long-term resources young adults need for embarking on a developmental path towards sustainable financial and subjective well-being (Hypothesis 3, H3). This is also justified by the early transition to financial independence among the Finnish young adult population, as mentioned above. Furthermore, as an addition to the research literature, we investigated whether the data reveal potential indirect effects related 
to the modified theoretical model of financial capability. We expected the relations between young adults' subjective financial situation at age 24-25 (T1) and their financial well-being and subjective well-being at age 26-27 (T2) to be mediated by the other components of financial capability, namely their financial confidence (or financial self-efficacy) and financial behavior (Hypothesis 4, H4).

\section{Method}

\section{Respondents}

Participants were drawn from the ongoing longitudinal "Finnish Educational Transitions Studies (FinEdu)" research project, mainly funded by the Academy of Finland. The present study uses data collected from young adults with a general upper secondary school background in 2011 (T1, age 24-25, $N=497$ ) and in 2013-2014 (T2, age 26-27, $N=528$ ). Participants who reported data at both time points were included in the final sample $(N=$ 415); the majority were female (69\%). Practically all participants had Finnish as their mother tongue (99.5\%). Parental socioeconomic status (SES) was measured based on participants' reports of their father's and mother's occupation and coded according to the Statistics Finland categorization (1989). The parental SES distribution was: (1) Selfemployed: 5\% fathers, 2\% mothers; (2) Blue-collar occupations (e.g., construction workers, mechanics): $24 \%$ fathers, $10 \%$ mothers; (3) Lower white-collar occupations (e.g., secretaries, salespersons, nurses): $13 \%$ fathers, $41 \%$ mothers; and (4) Higher white-collar occupations (e.g., physicians, teachers, lawyers, managers): $28 \%$ fathers, $25 \%$ mothers. Of 
fathers $31 \%$ and of mothers $25 \%$ were either not in employment (students, retired, or unemployed; i.e., those with a low income) or their occupation was unknown.

\section{Study design}

The FinEdu research project began in 2004 with data collections aimed at all second-year general upper secondary school (i.e., academic track) students resident in one middle-sized city in central Finland. The present study utilizes data collected in spring 2011 (T1) and from late autumn 2013 to spring 2014 (T2), and thus the data collections were separated by an interval of 2,5 years. In both data collections, participants were given self-report paper questionnaires to be returned by mail, although the cover letter also offered the option of participating online. In T1, 712 participants were contacted and after considerable effort, including a series of postcards, emails, text messages and telephone reminders as well as short telephone interviews implemented over a two-month period, 497 questionnaires, accounting for $70 \%$ of the total sample, were returned. Participation was motivated with a gift voucher and by raffles of gift certificates. At T2, 711 participants were contacted and after similar reminders, 528 questionnaires, accounting for $74 \%$ of all subjects, were returned.

The FinEdu research project follows general ethical guidelines. Participants signed an informed consent and could withdraw their participation at any time. For the study variables of subjective well-being and subjective financial situation, attrition was analyzed by comparing participants who took part in the study at both measurement points with those for whom data were missing at either measurement point. No significant differences 
were observed between participants who took part in the data collection at both time points and those who took part at only one time point either in subjective well-being at T1 $(t(483)$ $=.43, p=\mathrm{ns})$ or $\mathrm{T} 2(t(491)=1.91, p=\mathrm{ns})$ or subjective financial situation at $\mathrm{T} 1(t(485)=$ $1.12, p=\mathrm{ns})$ or $\mathrm{T} 2(t(523)=-.75, p=\mathrm{ns})$.

\section{Measures}

Financial confidence (or financial self-efficacy). Financial confidence (or financial selfefficacy) was measured at T2 in a straightforward manner using a single item (similar as to Serido et al., 2013): "How capable do you feel you are in handling financial matters?"

Responses were based on a 5-point Likert-type scale ranging from 1 (not at all) to 5 (very capable).

Financial behavior. Financial behavior was measured at T2 with five items, as in Shim et al. (2010) and Serido et al. (2013). Participants were asked to estimate how often they carry out certain money-related tasks and engage in positive financial behaviors, such as tracking monthly expenses, spending within a budget, and saving money each month for the future. Responses were based on a 5-point Likert-type scale ranging from 1 (never) to 5 (very often). The Cronbach's alpha coefficient was .72.

Financial well-being. Financial well-being was measured at T2 using three items, as in Shim et al. (2010; adopted from Shim et al., 2009), with responses rated on a 5-point Likert-type scale ranging from 1 (strongly disagree) to 5 (strongly agree). Participants were asked to indicate the extent to which they agreed or disagreed with each statement: "I am satisfied with the way I pay my bills", "I have difficulty paying for things", and "I am 
constantly worried about money". The two last items were reverse-coded. The Cronbach's alpha coefficient was .74.

Subjective financial situation. Participants' perception of their subjective financial situation was assessed at T1 and T2 with the question "Do you think your income covers your expenses at the moment?" Responses were based on a 5-point Likert-type scale ranging from 1 (poorly) to 5 (extremely well). Similar single-item measures have been used in previous studies to assess financial satisfaction, though consensus on whether to use single or multiple items is still lacking (Joo \& Grable, 2004).

Subjective well-being. Subjective well-being was assessed at T1 and T2 with the global “Satisfaction With Life Scale” (SWLS; Diener et al., 1985; Serido et al., 2013). Responses to five items such as "In most ways, my life is close to my ideal" were rated on a 7-point Likert-type scale ranging from 1 (strongly disagree) to 7 (strongly agree). The Cronbach's alpha coefficients were .88 (T1) and .93 (T2).

Parental SES (i.e., father's and mother's occupation). Parental SES was used as a control variable in the study and coded as described above.

\section{Data analysis}

The hypotheses were set and the longitudinal data collection planned to address the theoretical model of youth financial capability. Only participants who took part in both the Time 1 and Time 2 data collections were included in this study. The longitudinal data were analyzed with IBM SPSS Statistics 22 and Mplus 8 statistical programs (Muthén \& Muthén, 1998-2017). Following the theoretical model of financial capability and to test the 
hypotheses, the analyses consisted of Structural Equation Modeling and path models with manifest and latent variables. The model fit of the measurement model was estimated first, and the path model with the mediating effects thereafter. The mediation model was tested with a half-longitudinal design (Little, 2013), with the mediation effects of financial confidence (or financial self-efficacy) and financial behavior tested simultaneously between subjective financial situation at $\mathrm{T} 1$ and subjective and financial well-being at $\mathrm{T} 2$ using the Bayes corrected bootstrap procedure in the final modified model in Mplus (Cole \& Maxwell, 2003; Muthén \& Muthén, 1998-2017). This “multiple-mediator model” provides accurate information on mediating processes with multiple mediators (MacKinnon, Fairchild, \& Fritz, 2007). In this study, determining the longitudinal mediation effect of the two components of the theoretical model of financial capability from subjective financial situation to subjective and financial well-being was justified, as this allows testing for the theoretical model of financial capability.

Missing data were assumed to be missing-at-random (MAR), meaning that the available data was used to estimate the model using the full information maximum likelihood estimation (ML). Attrition analyses for the key study variables were conducted.

\section{Results}

\section{Descriptive results}

Table 1 shows the bivariate Pearson correlation matrix, means $(M)$ and standard deviations $(S D)$ for the study variables. These descriptive results showed a statistically significant 
decrease in subjective well-being over time $(F(1,400)=43.04, p<.001)$, but no statistically significant change in financial situation $(F(1,412)=2.21, p=n s)$. The bivariate correlations imply that subjective financial situation, financial well-being and subjective well-being are correlated. The other associations were significant, except that between subjective well-being at $\mathrm{T} 1$ and financial confidence (or financial self-efficacy) at $\mathrm{T} 2$.

Insert Table 1. here.

\section{Measurement model with validity and common method variance testing}

First, the fit of the measurement model of the latent constructs of subjective well-being, financial behavior and financial well-being was estimated. The standardized loadings of the five items forming the subjective well-being factor were $0.89,0.83,0.90,0.69$ and 0.65 at $\mathrm{T} 1$ and $0.93,0.89,0.92,0.79$ and 0.73 at $\mathrm{T} 2$. The standardized loadings of the five items forming the financial behavior factor were $0.33,0.37,0.45,0.82$ and 0.82 and for the three items forming the financial well-being factor $0.76,0.58$ and 0.80 . Due to the low loadings of the financial behavior items, the model was adjusted by following the modification indices to allow error terms of the financial behavior items to correlate. Thereafter, the standardized loadings of the five items forming the financial behavior factor were 0.37 , $0.44,0.54,0.66$ and 0.67 and the fit of the model was $\chi^{2}=480.01(125), p=0.000 ; \mathrm{CFI}=$ $.92 ; \mathrm{TLI}=.90 ; \mathrm{RMSEA}=.083(90 \% \mathrm{CI}=.08 ; .091) ; \mathrm{SRMR}=.06$, indicating satisfactory model fit. 
Convergent and discriminant validity of the latent factors were tested using the Average Variance Extracted (AVE) approach within Confirmatory Factor Analysis (Hair, Black, Babin, Anderson \& Tatham, 2006) and supported apart from the financial behaviour factor. The AVE of the subjective well-being factor was 0.63 at $\mathrm{T} 1$ and 0.73 at $\mathrm{T} 2$, for financial behaviour 0.30 , and for financial well-being 0.51 , indicating adequate convergence for the subjective well-being and financial well-being latent constructs, with the criterion of 0.5 or higher (Hair et al., 2006). Support for discriminant validity of the constructs was examined with the Fornell and Larcker (1981) technique, with AVE estimates for subjective well-being and financial well-being being greater than the squared correlations with other constructs in the model (Hair et al., 2006). Furthermore, the estimated factor loadings for subjective well-being and financial well-being were the expected 0.5 or higher (Kline, 2011). Finally, a test for common method bias was conducted with the single-common-method-factor-approach to control for the effects of an unmeasured latent methods factor (Podsakoff, MacKenzie, Lee \& Podsakoff, 2003). This widely used approach estimates method biases at the measurement level and controls for measurement error. The standardized coefficients in the common factor were not statistically significant in eight out of eighteen items, thus stating insignificant common method bias.

\author{
Mediation model of financial confidence (or financial self-efficacy) and financial \\ behavior between subjective financial situation and financial and subjective well- \\ being
}


The significant correlations between variables shown in Table 1 provided justification for testing possible mediating effects. Owing to the modification indices, the insignificant paths from financial confidence (or financial self-efficacy) to financial well-being and subjective financial situation at T2 were omitted from the model, as well as from subjective financial situation at $\mathrm{T} 1$ to financial behavior. The model fitted the data well $\left(\chi^{2}=\right.$ 461.10(173),$p=0.000 ; \mathrm{CFI}=.94 ; \mathrm{TLI}=.93 ; \mathrm{RMSEA}=.063(90 \% \mathrm{CI}=.06 ; .070) ; \mathrm{SRMR}$ $=.06)$ and is presented in Figure 2. Parental SES was controlled for to allow explanation of each of the dependent variables separately. The analyses yielded a similar fit to that without $\operatorname{SES}\left(\chi^{2}=524.97(173), p=0.000 ; \mathrm{CFI}=.92 ; \mathrm{TLI}=.88 ; \mathrm{RMSEA}=.072(90 \% \mathrm{CI}=.07\right.$; $.08) ;$ SRMR $=.06)$ and did not indicate any statistically significant results for the effect on the study variables of SES, except mothers' higher SES positively on financial confidence (or financial self-efficacy) and subjective financial situation at T1 $(p<0.001)$. Furthermore, the standardized coefficients of the model remained similar (differences in statistically significant coefficients were $<0.10)$.

Insert Figure 2. here.

The results showed significant paths from financial confidence (or financial self-efficacy) to financial behavior and to financial and subjective well-being ( $\mathrm{H} 1$ and $\mathrm{H} 2)$, thereby supporting the hypothesized theoretical model of financial capability. Statistically significant paths from subjective financial situation at age 24-25 to financial confidence (or financial self-efficacy) and financial well-being at age 26-27 were also found, and subjective financial situation and subjective well-being were inter-correlated in the cross- 
sectional data (H3). However, subjective well-being at age 24-25 was not associated with the components of financial capability at age 26-27.

Financial confidence (or financial self-efficacy) and financial behavior mediated subjective financial situation at age 24-25 and subjective well-being at age 26-27 (H4), thereby supporting the hypothesized mediation model. The indirect effect of subjective financial situation on financial well-being mediated by financial confidence (or financial self-efficacy) and financial behavior together was significant $(\beta=-0.04(p<.001$, lower $2.5 \% \mathrm{CI}=-.07--.02)$. The indirect effect on subjective well-being was also significant $(\beta=$ $-0.03(p<.05$, lower $2.5 \% \mathrm{CI}=-.06--.01)$. In sum, both of these components of the theoretical model of financial capability, together, mediated the longitudinal relationship between subjective financial situation and financial well-being and subjective well-being.

\section{Discussion}

This study investigated the financial situation and the novel theoretical framework of financial capability among a young adult population in Finland with longitudinal survey data. The support found in this study for hypotheses $\mathrm{H} 1$ and $\mathrm{H} 2$ highlights the applicability of the theoretical model of financial capability to this Finnish young adult age group. The importance of subjectively evaluated financial situation for financial capability, supporting $\mathrm{H} 3$, is also a significant result and an important contribution to the literature. Interestingly, subjective financial situation at age 24-25 was associated with financial confidence (or financial self-efficacy) two years later at age 26-27. Subjective well-being was not 
associated longitudinally with financial confidence (or financial self-efficacy) or with the other components of financial capability. Finally, the theoretical model of financial capability was also supported by the tested mediation model which showed indirect effects of subjective financial situation at age 24-25 on financial and subjective well-being at age 26-27 through the two mediators of financial confidence (or financial self-efficacy) and financial behavior (H4). However, young adults' subjective financial situation did not have a direct effect on their financial behavior, providing support for the significance of financial confidence (or financial self-efficacy) beyond only financial circumstances, and thus the applicability of the financial capability model in general.

This study contributes to addressing the call for research on youth financial capability in diverse sociohistorical contexts (Serido et al., 2013). Despite the ongoing economic turbulence, social and economic policies may reduce the negative impact that economic uncertainty can have on the financial situation of young adults (Blossfeld et al., 2005). For example, in societies with a strong public sector and welfare programs, such as Finland, fundamental rights to public services and support are already in place.

The results of this study also highlight the increasing need for research not only on socioeconomic circumstances but also on the individual's resources (i.e., subjective view of one's personal financial situation) as well as personal experiences of financial capability, both being important for young adults' well-being. Given the persistence of societal financial uncertainty and the increasing financial problems facing young people, it is crucial to identify the factors that contribute to financial capability in this age group as critical for positive youth development. 


\section{Practical implications}

Several studies have shown that, in general, young people's financial capability is at a rather low level (Atkinson et al., 2006; Lusardi et al., 2010). Recent trends are likely to make the need for financial literacy skills even more important in the future. For example, future generations are likely to face more challenging financial choices, given the growing diversity in the range of financial products offered to consumers. Financial education will therefore play a key role in enabling people to understand complicated products and services and protecting from financial abuse. Future generations are likely to bear even more financial risks during their lives as welfare services decline and economic and job prospects remain uncertain. Growing wealth and income inequality will put socioeconomically disadvantaged groups at a further disadvantage, rendering financial literacy more important than ever. Providing youth with financial education is a 21 st century requirement. This is further underlined by the growing need for ethics in financial issues occasioned by the recent financial crisis.

Public concern about the low financial capability of young people is partially related to shrinking support systems and concomitant increased individual responsibility (OECD, 2012). In response to this situation, several OECD actions have been taken to foster the development of financial capability, such as incorporating financial capability into the worldwide Programme for International Student Assessment (PISA) study (OECD, 2012). In the PISA study, financial literacy fortunately includes not only knowledge and understanding of financial concepts and skills, but also building the motivation and selfconfidence to use that knowledge and understanding of sensible decision-making in different finance-related situations and contexts. This enables participation in financial 
activities and increases individual and societal financial well-being (OECD, 2012). On the long run, it is expected that the factors contributing to and supporting youth financial independence and fostering youth financial well-being are grounded in financial education and the childhood home. Financial capability calls for more than mere objective or even subjective financial knowledge, as real-world financial behavior and subjective perceptions of one's personal financial situation also play an important role.

\section{Limitations and future research}

Despite the interesting findings and contribution to the literature on the theoretical model of financial capability, this study has the following main limitations. First, the young adults studied all had an upper secondary (high school) background, in other words they had all followed an academic track after compulsory education. Previous research (Lusardi et al., 2010) has shown that graduation from high school is associated with higher financial literacy. The background of the sample also explains the high proportion of female participants, as it reflects the overall gender distribution of the students in Finland's general upper secondary schools, where 57\% are females (Statistics Finland, 2010).

Secondly, limitations concerning methodology need to be addressed. In the measurement model, convergent and discriminant validity of the financial behaviour latent factor was at a low level, although theoretical justifications and an improved model fit following the given modification indices give support for this latent factor. Furthermore, the limited information obtained from some of the measures constrained the extent of the analyses and comparability with similar studies, such as that of Serido and colleagues (2013). Future questionnaire studies might address these themes with a broader range of 
items. For instance, this study did not include measures of objective or subjective financial knowledge, introduced as the starting points in the development of financial capability (Serido et al., 2013). Furthermore, the other two factors of self-beliefs, perceived behavioral control and financial attitude, were not included in the present study. These aspects merit attention in future studies, and may also explain the unexpected finding that subjective financial situation did not have a direct effect on financial behavior. Further studies on the applicability of the financial capability model are needed, also to test alternative direct and indirect paths between the study variables. Furthermore, while financial satisfaction and perceived personal financial situation have in many studies been assessed appropriately with a single item, the measure used in the present study captures only the evaluation of income relative to expenses. A comprehensive construct with multiple measures should be used in following studies, in order to investigate different dimensions of experienced financial situation. Finally, the study did not include longitudinal data on the main financial capability measures, i.e., financial confidence (or financial self-efficacy), financial behavior and financial well-being. Further research with longitudinal data to examine the development of financial capability is called for.

Finally, the country context must be taken into consideration as Finnish youth are able to benefit from broad-based state financial support, a factor that clearly influences their financial capability in young adulthood. Therefore, generalizations of the present findings to non-Nordic countries can only be tentative.

\section{Conclusions}


The present study contributes to the understanding of youth financial capability from a theoretical perspective as a dynamic and complex process with an emphasis on subjective experiences of financial confidence and personal financial situation, as well as well-being. The need to study this theoretical framework empirically in the human sciences is highlighted in the initiative taken by Serido, Shim and Tang (2013). This study builds on their work in the highly relevant and topical research field of youth financial capability by analyzing longitudinal data from a young adult sample in Finland. The economic recession, early transitions to financial independence and the financial support offered by the Nordic welfare state emphasize the importance of the Finnish societal context in terms of youth financial capability. In this respect, in addition to the fact that the theoretical framework of financial capability was supported in the present study, the addition of the assessment of subjective financial situation in the model of financial capability is supported. The study also extends previous research by demonstrating that while financial confidence does not directly relate to financial well-being, it is the mediating effect of financial confidence and financial behavior, together, from subjective financial situation to subjective and financial well-being, that is the novel contribution of the present longitudinal study.

\section{Acknowledgements}

The authors would like to thank Professor Asko Tolvanen, University of Jyväskylä, Finland, for statistical advice on the analyses of the present study. 


\section{Funding}

This work was supported by the Ella and Georg Ehrnrooth Foundation for the first author; and by the Academy of Finland for the Finnish Educational Transitions (FinEdu) research project [grant numbers 273872, 307523 and 308351] for the second author.

\section{References}

Arnett, J. J. (2000). Emerging adulthood: A theory of development from the late teens through the twenties. American Psychologist, 55, 469-480.

Arnett, J. J. (2004). Emerging adulthood. The winding road from the late teens through the twenties. New York: Oxford University Press.

Asaad, C. T. (2015). Financial literacy and financial behavior: Assessing knowledge and confidence. Financial Services Review, 24, 101-117.

Ashby, J. S., Schoon, I., \& Webley, P. (2011). Save now, save later? Linkages between saving behavior in adolescence and adulthood. European Psychologist, 16(3), 227237.

Atkinson, A., McKay, S., Kempson, E., \& Collard, S. (2006). Levels of financial capability in the UK: Results of a baseline survey. Financial Services Authority, Consumer Research 47. 
Bandura, A. (1977). Self-efficacy: Toward a unifying theory of behavioral change. Psychological Review, 84(2), 191-215.

Bandura, A. (1989). Social cognitive theory. In R. Vasta (Ed.), Annals of Child Development (pp. 1-60). Greenwich, CT: JAI Press.

Blossfeld, H.-P., Klijzing, E., Mills, M., \& Kurz, K. (Eds.) (2005). Globalization, uncertainty and youth in society. London: Routledge.

Choroszewicz, M., \& Wolff, P. (2010). 51 million young EU adults lived with their parent(s) in 2008. Eurostat/Statistics in focus, 50/2010. Population and social conditions. Retrieved from Eurostat website http://epp.eurostat.ec.europa.eu/portal/page/portal/product_details/publication?p_prod uct_code $1 / 4 \mathrm{KS}-\mathrm{SF}-10-050$

Cole, D. A., \& Maxwell, S. E. (2003). Testing mediational models with longitudinal data: Questions and tips in the use of structural equation modeling. Journal of Abnormal Psychology, 112(4), 558-577.

Conger, R. D., Conger, K. J., \& Martin, M. J. (2010). Socioeconomic status, family processes, and individual development. Journal of Marriage and Family, 72, 685-704.

Conger, R. D., Conger, K. J., Matthews, L. S., \& Elder, G. H., Jr. (1999). Pathways to economic influence on adolescent adjustment. American Journal of Community Psychology, 27, 519-541.

Cowan, P. A. (1991). Individual and family life transitions. A proposal for a new definition. In P. A. Cowan \& M. Hetherington (Eds.), Family transitions (pp. 4-30). Hillsdale, NJ: Lawrence Erlbaum Associates. 
Cummins, R. A. (2000). Personal income and subjective well-being: A review. Journal of Happiness Studies, 1, 133-158.

Cunnien, K. A., MartinRogers, N., \& Mortimer, J. T. (2009). Adolescent work experience and self-efficacy. International Journal of Sociology and Social Policy, 29(3/4), 164175.

Danzinger, S., \& Ratner, D. (2010). Labor market outcomes and the transition to adulthood. Future of Children, 20, 133-157.

Diener, E., \& Biswas-Diener, R. (2002). Will money increase subjective well-being? A literature review and guide to needed research. Social Indicators Research, 57, 119169.

Diener, E., Emmons, R. A., Larsen, R. J., \& Griffin, S. (1985). The Satisfaction with Life Scale. Journal of Personality Assessment, 49, 71-75.

Dixon, M. (2006). Rethinking financial capability. Lessons from economic psychology and behavioural finance. Retrieved from http://www.ippr.org/publications/rethinkingfinancial-capabilitylessons-from-economic-psychology-and-behavioural-finance

Elder, G. H., Jr. (1998). The life course as developmental theory. Child Development, 69, $1-12$.

Elder, G. H., Jr., \& Caspi, A. (1988). Economic stress in lives: Developmental perspectives. Journal of Social Issues, 44, 25-45.

Finnish National Board of Education (2012). Education structure. Retrieved from http://www.oph.fi/english/education/overview_of_the_education_system FINRA (2009). Financial capability in the United States: National survey - Executive summary. Washington, DC. Retrieved from 
www.finrafoundation.org/web/groups/foundation/@foundation/documents/foundation/ p120535.pdf

Fornell, C., Larcker, D. F. (1981). Evaluating structural equation models with unobservable variables and measurement error. Journal of Marketing Research 18(1), 39-50.

Friedline, T. L., Elliott, W., \& Nam, I. (2011). Predicting savings from adolescence to young adulthood: A propensity score approach. Journal of the Society for Social Work and Research, 2(1), 1-22.

Gutter, M., \& Copur, Z. (2011). Financial behaviors and financial well-being of college students: Evidence from a national survey. Journal of Family and Economic Issues 32(4), 699-714. •

Hair, J. F., Jr., Black, W. C., Babin, B. J., Anderson, R. E., \& Tatham, R. (2006). Multivariate Data Analysis. New York: Pearson International Edition.

Heckhausen, J. (1999). Developmental regulation in adulthood. Age-normative and sociostructural constraints as adaptive challenges. Cambridge: Cambridge University Press.

Hellevik, T., \& Settersten, R. A., Jr. (2012). Life planning among young adults in 23 European countries: The effects of individual and country security. European Sociological Review, 29, 923-938.

Huston, S. J. (2010). Measuring financial literacy. The Journal of Consumer Affairs, 44(2), $296-316$.

Johnson, E., \& Sherraden, M.S. (2007). From financial literacy to financial capability among youth. Journal of Sociology and Social Welfare, 34(3), 119-145. 
Joo, S., \& Grable, J. E. (2004). An exploratory framework of the determinants of financial satisfaction. Journal of Family and Economic Issues, 25(1), 25-50.

Jorgensen, B. S., Jamieson, R. D., \& Martin, J.F. (2010). Income, sense of community and subjective well-being: Combining economic and psychological variables. Journal of Economic Psychology, 31(4), 612-623.

Kim, J., Garman, E. T., \& Sorhaindo, B. (2003). Relationships among credit counseling clients' financial well-being, financial behaviors, financial stressor events, and health. Financial Counseling and Planning, 14, 75-87.

Kline, R. B. (2011). Principles and Practice of Structural Equation Modeling. New York: The Guilford Press.

Lee, J. C., \& Mortimer, J. T. (2009). Family socialization, economic self-efficacy, and the attainment of financial independence in early adulthood. Longitudinal and Life Course Studies 1(1), 45-62.

Leskinen, J., \& Raijas, A. (2006). Consumer financial capability - a life cycle approach. In European Credit Research Institute (Ed.), Consumer financial capability: Empowering European consumers (pp. 8-23). Brussels: European Credit Research Institute. Retrieved from http://www.ecri.eu/new/system/files/FinCap_Workshop_I_papers.pdf Lintonen, T. P., Wilska. T.-A., Koivusilta, L. K., \& Konu, A. I. (2007). Trends in disposable income among teenage boys and girls in Finland from 1977 to 2003. International Journal of Consumer Studies, 31, 340-348.

Little, T. D. (2013). Longitudinal Structural Equation Modeling. New York: Guilford Press. 
Luhmann, M., Schimmack, U., \& Eid, M. (2011). Stability and variability in the relationship between subjective well-being and income. Journal of Research in Personality, 45, 186-197.

Lusardi, A., Mitchell, O. S., \& Curto, V. (2010). Financial literacy among the young. The Journal of Consumer Affairs, 44(2), 358-380.

Luyckx, K., De Witte, H., \& Goossens, L. (2011). Perceived instability in emerging adulthood: The protective role of identity capital. Journal of Applied Developmental Psychology, 32, 137-145.

MacKinnon, D. P., Fairchild, A. J., \& Fritz, M. S. (2007). Mediation analysis. Annual Review of Psychology, 58, 493-614.

Mayer, K. U. (2003). The sociology of the life course and lifespan psychology: Diverging or converging pathways? In U. M. Staudinger \& U. Lindenberger (Eds.), Understanding human development: Dialogues with lifespan psychology (pp. 463481). Boston: Kluwer.

Ministry of Education and Culture (2010). Ei paikoillanne, vaan valmiit, hep! Koulutukseen siirtymistä ja tutkinnon suorittamista pohtineen työryhmän muistio [Not on your marks but ready, set, go! A memo of a working group pondering the transition to education and getting a degree]. Helsinki: Ministry of Education and Culture, 11. Retrieved from http://www.minedu.fi/OPM/Julkaisut/2010/opintojen_nopeuttaminen.html Ministry of Education and Culture (2014). Student Survey 2014. Higher education students' income and studies. Helsinki: Ministry of Education and Culture, 10. Retrieved from http://80.248.162.139/OPM/Julkaisut/2014/Opiskelijatutkimus_2014.html 
Morgan, F. W., Schuler, D. K., \& Stoltman, J. J. (1995). A framework for examining the legal status of vulnerable consumers. Journal of Public Policy \& Marketing, 14(2), $267-277$.

Muthén, L. K., \& Muthén, B. O. (1998-2017). Mplus Users Guide (8th ed). Los Angeles, CA: Muthén \& Muthén.

Nussbaum, M. (2002). Capabilities and human rights. In P. De Greiff \& C. Cronin (Eds.), Global justice and transnational politics: Essays on the moral and political challenges of globalization (pp.117-149). Cambridge, MA: MIT Press.

OECD (2012). PISA 2012 financial literacy assessment framework. Retrieved from http://www.oecd.org/pisa/pisaproducts/46962580.pdf

Official Statistics of Finland (2014). Labour force survey (e-publication). November 2014, Appendix table 16. Unemployment rates by sex and age 2013/11 - 2014/11. Helsinki: Statistics Finland. Retrieved from http://www.stat.fi/til/tyti/2014/11/tyti_2014_11_2014-12-23_tau_016_en.html

Otto, A. (2013). Saving in childhood and adolescence: Insights from developmental psychology. Economics of Education Review, 33, 8-18.

Podsakoff, P. M., MacKenzie, S. B., Lee, J. Y., \& Podsakoff, N. P. (2003). Common method biases in behavioral research: a critical review of the literature and recommended remedies. Journal of Applied Psychology, 88(5), 879-903.

Seay, M. C., \& Robb, C. A. (2013). The effect of objective and subjective financial knowledge on high-cost borrowing behavior, Financial Planning Review, 6(4), 1-19. Sen, A. (1993). Capability and well-being. In M. Nussbaum \& A. Sen. (Eds.), The quality of life (pp. 30-53). Oxford: Clarendon Press. 
Serido, J., Shim, S., \& Tang, C. (2013). A developmental model of financial capability: A framework for promoting a successful transition to adulthood. International Journal of Behavioral Development, 37(4), 287-297.

Sherraden, M. S., Johnson, L., Guo, B., \& Elliott, W., III (2011). Financial capability in children: Effects of participation in a school-based financial education and savings program. Journal of Family and Economic Issues, 32, 385-399.

Shim, S., Barber, B. L., Card, N. A., Xiao, J. J., \& Serido, J. (2010). Financial socialization of first-year college students: The roles of parents, work, and education. Journal of Youth and Adolescence, 39, 1457-1470.

Shim, S., Xiao, J. J., Barber, B. L., \& Lyons, A. C. (2009). Pathways to life success: A conceptual model of financial well-being for young adults. Journal of Applied Developmental Psychology, 30, 708-723.

Smith, N. C., \& Cooper-Martin, E. (1997). Ethics and target marketing: The role of product harm and consumer vulnerability. Journal of Marketing 61(3), 1-20.

Statistics Finland (1989). Classification of Socioeconomic Status. Handbook 17.

Statistics Finland (2010). Education 2009. Retrieved from http://tilastokeskus.fi/til/lop/20091op_2009_2010-06-11_tie_001_en.html

UNICEF Office of Research (2014). Children of the recession: The impact of the economic crisis on child well-being in rich countries. Florence: Innocenti Report Card 12.

Wilska, T.-A., \& Lintonen, T. (2016). The gender gap in teenagers' incomes. A 30-year trend in Finland 1983-2013. Journal of Youth Studies, 19(4), 421-437.

Xiao, J. J., Serido, J., \& Shim, S. (2011). Financial education, financial knowledge and risky credit behavior of college students. In D. J. Lamdin (Ed.), Consumer knowledge 
and financial decisions: Lifespan perspectives (pp. 113-128. International Series on Consumer Science. New York: Springer. 


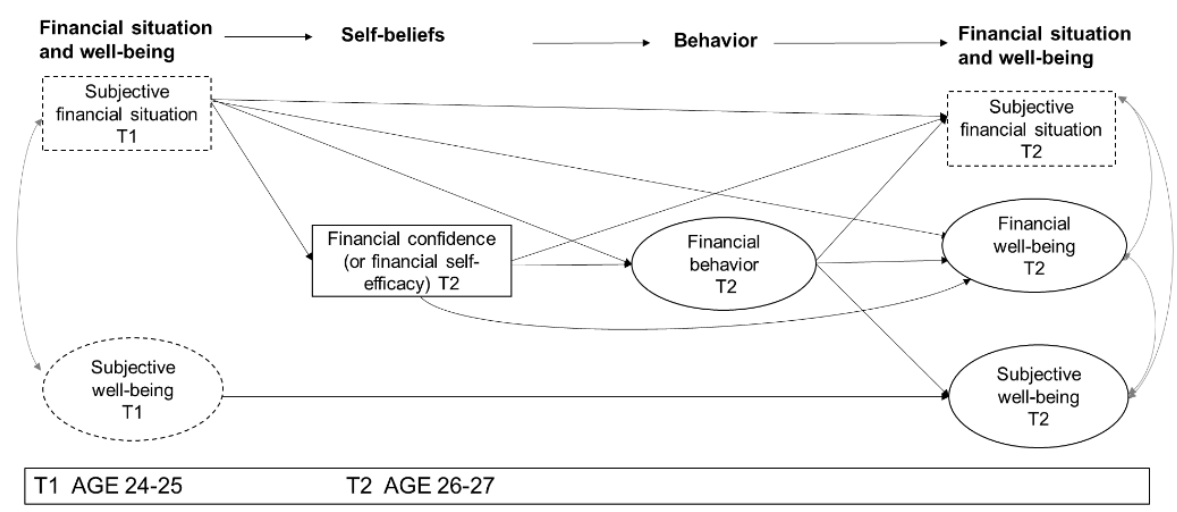

Fig. 1. The adopted theoretical model of financial capability from Serido et al., 2013 used in the present study, with differentiated variables marked with a dashed line. 


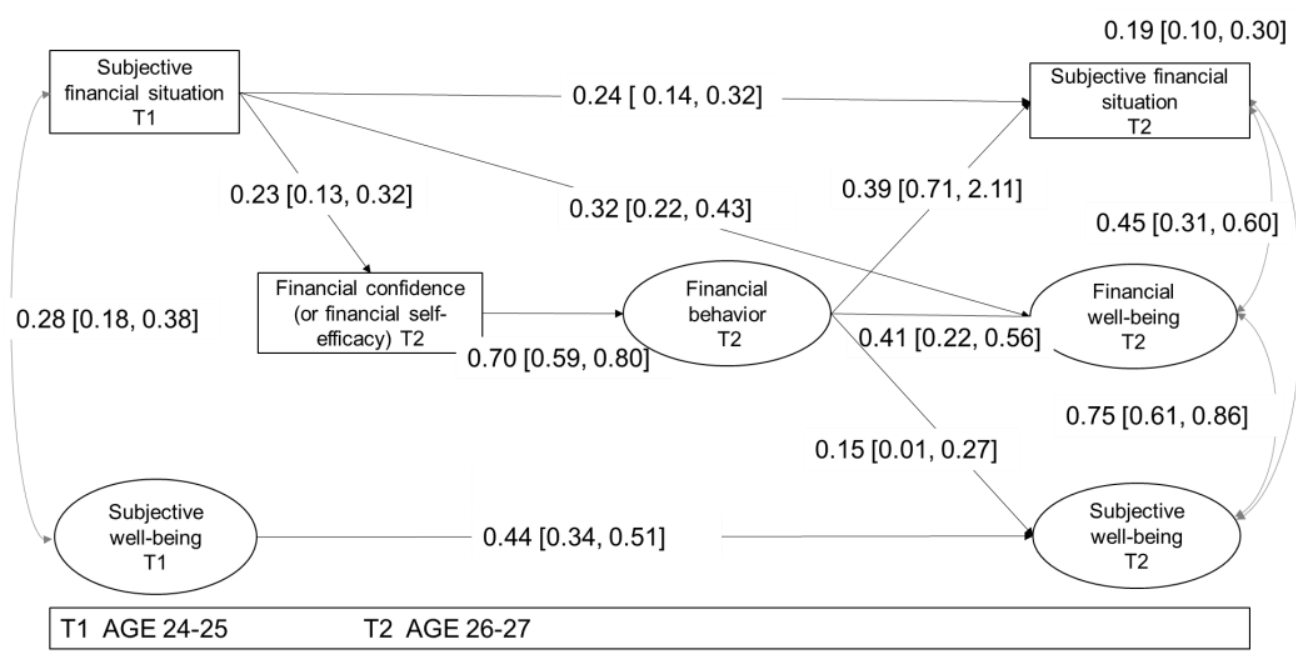

Fig. 2. $N=415$. Model of financial capability with subjective financial situation and subjective well-being at ages 24-25 predicting financial confidence (or financial selfefficacy), financial behavior, subjective financial situation, financial well-being and subjective well-being at ages 26-27. The paths and associations are presented as standardized estimates. Nonsignificant effects are not displayed. The $95 \%$ confidence interval is in brackets.

Notes. Model fit $\left(\chi^{2}=461.10(173), p=0.000 ;\right.$ CFI $=.94 ;$ TLI $=.93 ;$ RMSEA $=.063(90 \%$ $\mathrm{CI}=.06 ; .070) ; \mathrm{SRMR}=.06)$. 
Table 1. Scales, means, standard deviations, and correlations of the study variables.

\begin{tabular}{|c|c|c|c|c|c|c|c|}
\hline Variable & 1 & 2 & 3 & 4 & 5 & 6 & 7 \\
\hline 1 Subjective financial situation (T1) & - & & & & & & \\
\hline 2 Subjective well-being (T1) & $.26^{* *}$ & - & & & & & \\
\hline 3 Financial confidence $^{1}(\mathrm{~T} 2)$ & $.23^{* *}$ & .10 & - & & & & \\
\hline 4 Financial behavior (T2) & $.18^{* *}$ & $.13^{* *}$ & $.51^{* *}$ & - & & & \\
\hline 5 Subjective financial situation (T2) & $.33^{* *}$ & $.13^{* *}$ & $.30^{* *}$ & $.30^{* *}$ & - & & \\
\hline 6 Financial well-being (T2) & $.28^{* *}$ & $.12^{*}$ & $.19^{* *}$ & $.18^{* *}$ & $.36^{* *}$ & - & \\
\hline 7 Subjective well-being (T2) & $.19^{* *}$ & $.49^{* *}$ & $.11^{*}$ & $.19^{* *}$ & $.26^{* *}$ & $.37^{* *}$ & - \\
\hline Scale & $1-5$ & $1-7$ & $1-5$ & $1-5$ & $1-5$ & $1-5$ & $1-7$ \\
\hline Mean & 3.33 & 5.10 & 4.27 & 3.42 & 3.43 & 3.54 & 4.66 \\
\hline St. dev. & 1.19 & 1.22 & .90 & .96 & 1.21 & 1.13 & 1.32 \\
\hline
\end{tabular}

Note: $N=415 .{ }^{1}=$ Financial confidence (or financial self-efficacy)

$* * p<.01, * p<.05$. 
